\title{
Clay Panicum Maximum Integration, An Artistic Conjecture in Ghana
}

\author{
Ibrahim Yahaya, Ama Asabea Djokoto and Rudolf Steiner* \\ College of Art and Built Environment \\ Kwame Nkrumah University of Science and Technology. Kumasi \\ rudsteiny@yahoo.com
}

\begin{abstract}
This piece of writing is on clay panicum maximum integration for flower vase production, as the cultural presupposition in Ghana. In discussing the paper, some attempts have been made to examine the nature and dynamics of traditional pottery and basketry works from panicum maximum, as well as their appreciation as human achievement. There is also a general overview on clay work and panicum maximum work in Ghana, outlining in particular where they are found, and the varieties that exist. The authors maintained that clay panicum maximum integration is a self-motivated and adoptable process which has a social heritage component as well as a religious height. Some of the assumptions drawn are that clay panicum maximum integration is a component of our integrated systems and tradition, but has undergone noteworthy variations over the past decades.
\end{abstract}

Keywords: panicum maximum, dyeing, clay pot, decoration and integration.

DOI: $10.7176 / \mathrm{ADS} / 97-01$

Publication date: December $31^{\text {st }} 2021$

\section{Introduction}

The scope of the nature and function of clay and panicum maximum is very wide and its gears are many, wideranging and multifaceted. For this reason, no comprehensive and convincing explanation of clay and panicum maximum has ever been advanced, although many explanations have been presented in efforts to create awareness about the nature and functions of clay and panicum maximum. The multifaceted nature and function of clay and panicum maximum nonetheless, many people look at clay and panicum maximum products as just artifacts and define them from artistic perspectives, others define them in terms of tradition and cultural style while others religion. Clay and panicum maximum integrated products making has been a highly valued skill throughout Ghana. In Ancient Egypt and India, pottery making was divided into specialist guilds according to the materials and techniques. In some cultures, like the Romans and the Egyptians, techniques and skills are shrouded in secrecy, describing and giving identity to the artists. The objective of this piece of writing is to project the nature, and function of clay and panicum maximum in complementing each other in product development in the Ghanaian culture.

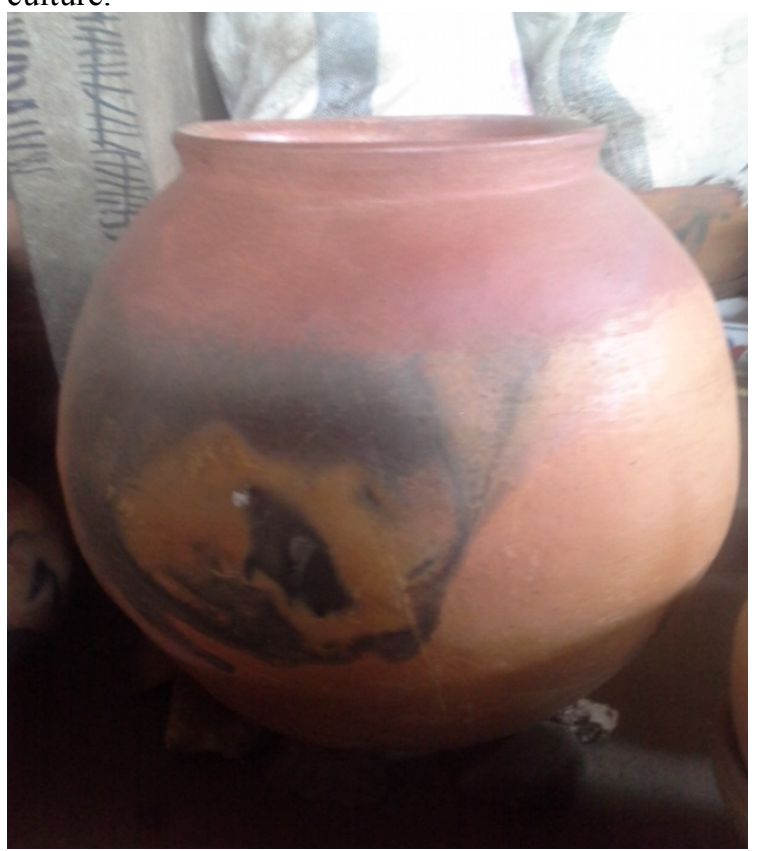

Clay pot

The fascinating story of clay pots spans the globe, present in all cultures and at all times through history. 
James Amoah (2015) in a personal communication, said that pots have been made on all continents over several thousand years ago. People in different parts of the globe used earth materials available to them, and developed different designs and approaches to the craft in accordance with the belief, need and purpose. The exact origin of pots is difficult to trace. In Africa, E.C Nyarko (2020) in a presentation explained that pots are also products evolving. The growth of pottery art can be traced from four perspectives: pottery making as an art of the mind with close associations to the inspiration of human perfection, pot making for intellectual and moral growth, pot making as an art and pot making as a way of life, moral, intellectual and spiritual, of a self-motivated group of people. Oakley (2012), revealed that pottery is one of the most widespread categories of objects found by archaeologist during excavations, and has the capability of providing important data about human history.

\section{Pots in Ghana}

The most common pots found in Ghana in almost all the cultures are the water pots, grinding pots, cooking pots, pito pots, palm wine pots and religious and ritual pots. These are particularly common in almost all the sixteen regions in Ghana.

In the past, pots produced in Ghana, can be grouped in to three. These are royal pots, religious and domestic pots. The royal pots are that made for the royals to be used by the Chiefs and people of the ruling palace, ritual pots are those made mainly for the priests, shrines and for religious purposes. Domestic pots are those made for use in the home and are made by women having the skill to produce pots. Ritual and religious pottery production is shrouded in secrecy and in most societies the domain of the aged women who have passed the stage of child bearing.

\section{Pottery Decorations}

Pottery can be examined on the principles of different qualities, such as the shape, form, type of surface, the colour, drawn patterns on them and the decorative style in general. All these elements, when carefully examined comprehensively for a specific culture and period, would enable us appreciate the creative progress of a particular society. It may also help professionals to establish the source of a pottery fragments that are located far away from their production site.

According to Oakley (2012), the awakening of interest in pottery traditions and in new pottery composition, has been generally believed or organized as an art form. Some contemporary potters were earlier times been artist in other disciplines. Pottery exhibitions were scarcely organized in the past, and exhibitors developed less interest in the functionality of the products as they were more concerned with decorations on pottery wares. The improvement of vase painting saw increasing decoration in ancient Greek pottery. The pottery of the ancient Greek was of great significance or valued for both integral aesthetic of their forms and decorations, and for the exposure they created on the progress of Greek pictorial arts. Pottery production and decoration in the archaic and classical Greece incorporated a first black- figure pottery, followed by other decorative techniques like redfigure pottery and white ground techniques. Techniques like west slope wares were the features belonging typically of the Hellenistic period, which saw vases painting decreased. Geometric pottery decoration thrived in the $8^{\text {th }}$ and $9^{\text {th }}$ century BC. It was distinguished by new elements, breaking with characterization of the Minoan and Mycenae civilization periods; bends and curves triangles and other geometrical decorations as opposed to the prevalent circular features of the techniques.

Ardmore ceramics (2010), also mentioned that pottery production in Africa started around $7^{\text {th }}$ millennium $\mathrm{BC}$ and continued to present time in the different regions of the continent. Traditionally African pottery was made by women. Clay was processed thoroughly by hand, modelled and shaped into the desired forms and applied decorations on them. Embellishing of pottery wares was and still a usual decorative technique applied on traditional pots. Some potters applied plants dyes to colour their wares as decorations, the dyes were randomly splashed on the ware after firing. Other potters also attached animal or human figures to the pots to give them characters or served as beaks or handles. Other materials like basketwork were also attached to the pots to serve as covers, handles and stands for functionality and decorative purposes.

Olsson (1984), is of the view that traditional African pots, having discovered their useful forms, are usually decorated to please the eye, or the decorations could have a spiritual significance. Traditional potteries were usually unglazed, but the smoother pots were polished or burnished with smooth pebbles to obtain a shiny surface. Burnishing were done usually at the leather- hard state to closely seal pores and strengthen the walls, as well as make them shiny and watertight. Incised decoration was also done at the leather- hard state with sharp tool, and sometimes combined with impressed designs, pressed with bracelets or beaded bangles. Other designs were also stamped and dragged over the wet surface of the wares. Alternated triangular pattern designs mostly countless in variations, are commonly found on traditional pottery forms as decorations. Other abstract decorated patterns like zig-zag lines, rectangles and occasionally animal figures, however could have been influenced by the period of ancient human culture. 


\section{Panicum maximum (Guinea grass)}

Ferreira (2005) said that panicum maximum is the term that describes a perennial grass of the family of poaceae species of panicum. A personal conversation Angmor had with Steiner (2014) pointed out that, the specie panicum maximum is popularly known as Guinea grass. Ferreira (2005), again said Panicum is derived from a Latin name for millet (panicummiliaceum) and maximum refer to the great height that this plant attains. The stem of this robust grass can reach a height up to 2 meters.

Russell et all (1991) explained that panicum maximum (Guinea grass) is a perennial tufted grass with a short, creeping rhizome, The stem of the grass are robust and can reach a height of up to 2 meters.

Russell et all (1991) concluded that panicum maximum (Guinea grass) prefers a fertile soil and is well adapted to a wide variety of conditions. It grows especially well in shaded, damp areas under trees and shrubs and it is often gotten along rivers.

In a personal communication Steiner (2014) revealed that panicum maximum (Guinea grass) is mostly located around ponds in the Northern Region of Ghana. According to him, from ancient time panicum maximum (Guinea grass) has been linked to human livelihood, fulfilling the needs for beds, containers for grains, for roofing of houses, and as feed for cattle in most cultures.

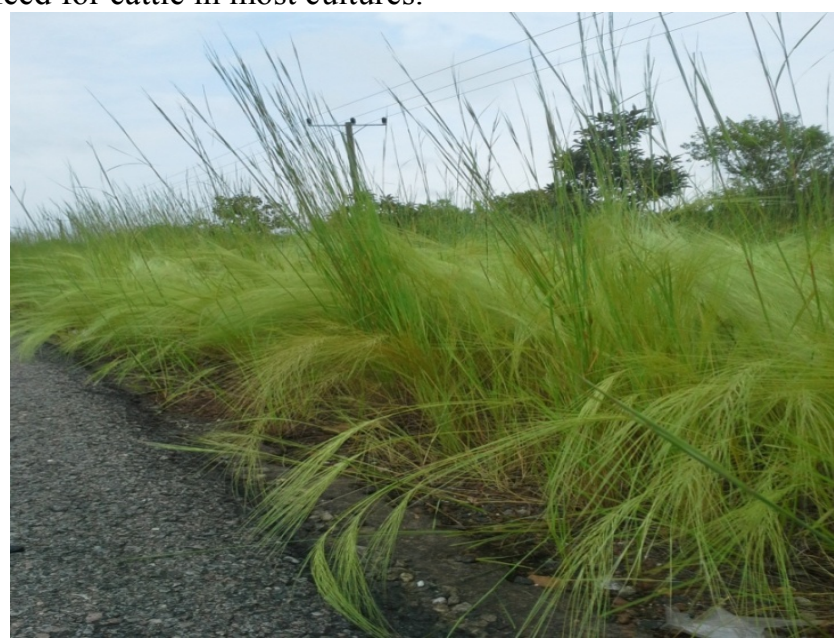

Panicum Maximum

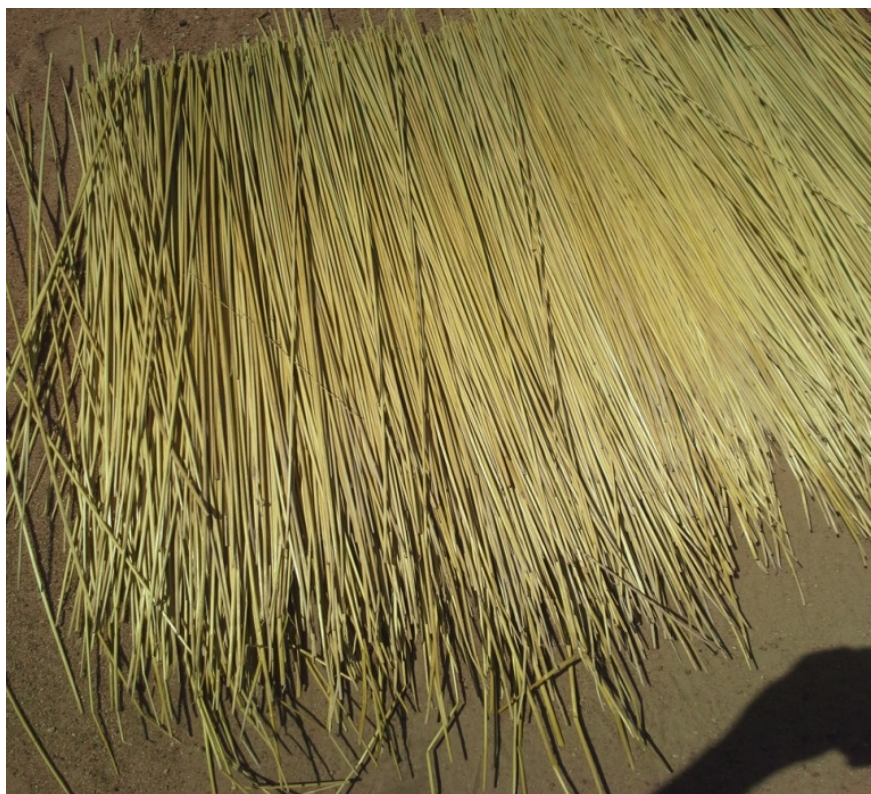

Panicum maximum after harvesting, removal of inflorescence and drying

\section{Processing of Panicum maximum (Guinea grass)}

Panicum maximum (Guinea grass) originates from Africa, but it is presently found and cultivated in almost all tropical parts of the world. This was confirmed by Lazarides (1980), when he said that Panicum maximum has economic importance as a major forage grass, which is cultivated and grown throughout the tropics. It is a hardy, vigorous plant producing high yield of nutritious fodder, which is suitable for grazing or cut as green feed for 
animals. He further explained and agreed with Alderson et all (1993), in saying that the nutritive value of Panicum maximum declines so rapidly with age and over time, it dies if continually grazed over close to the ground by cattle, goats and other animals that depend on it.

Steiner (2014), as cited by Angmor, said bleaching of Panicum maximum (Guinea grass) is done to improve material colour quality and dyeing with sued dyes to add colour and strength of the material. Steiner (2014), concluded that different technologies have been developed by artist in different locations to meet the need for processing and fabrication.

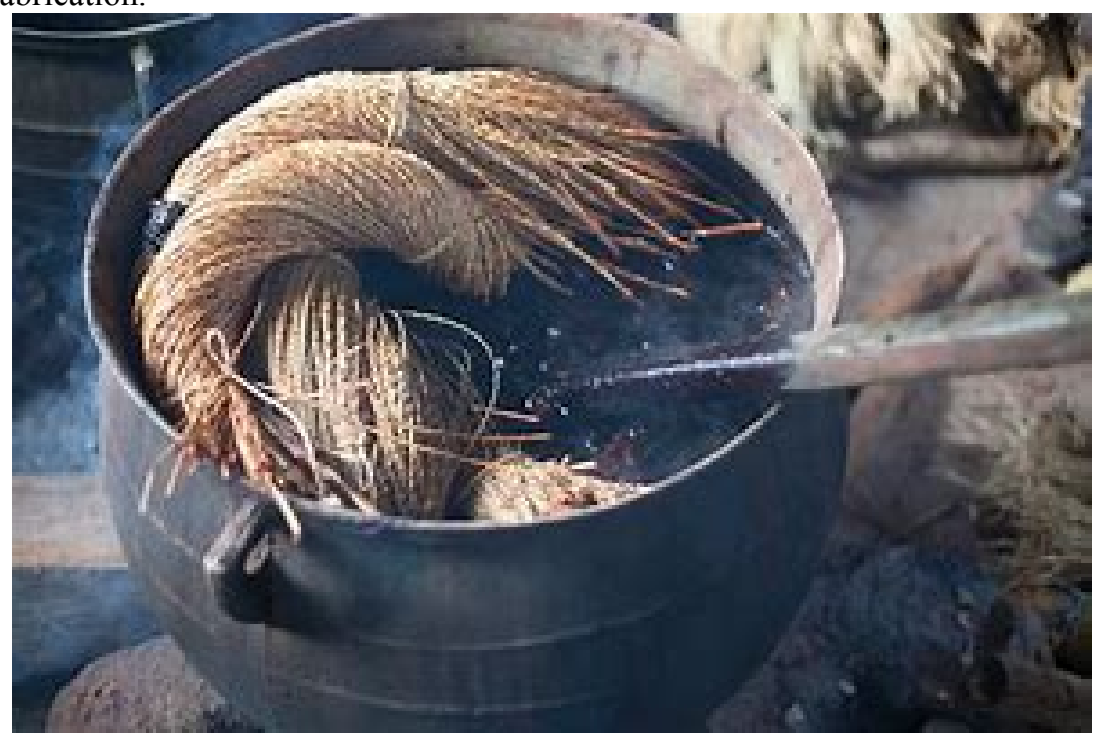

Dyeing of panicum maximum with local plant dye

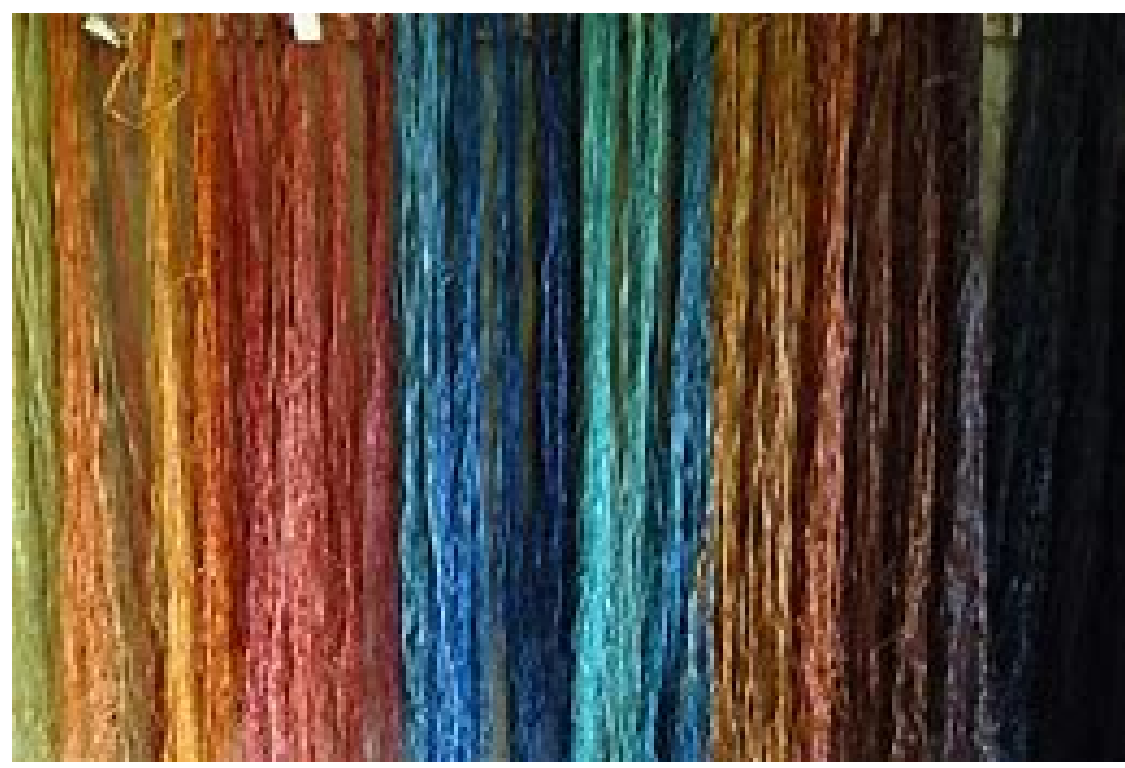

Different shades of dyed panicum maximum

\section{Uses of Panicum Maximum (Guinea grass)}

Daasaah (2009), was of the view that Panicum Maximum is known in Ghana as Guinea grass (straw) and can be found in almost all the Regions in Ghana. They are wild plants which are usually grown at the banks of rivers and streams, along the roads and waterlog areas. They are local materials used for weaving sun hats, fruit baskets, shopping bags, ladies hand bags, baby rattles, straw plates and hand fans as well as used to prepare hay for animal feeds. Steiner (2014), as cited by Angmor also explained that Guinea grass is a very pliable material and can be twisted and manipulated to form useful and decorative artifacts. Steiner (2014), continued to explain that when water is introduced on Guinea grass, it attains more flexibility and strength to be able to be manipulate effectively. He further narrated that most of the craftsmen working with panicum maximum (Guinea grass), engaged in off-loom weaving. The on-loom weaving employs the use of a loom to give the Guinea grass support and tension as one works. 


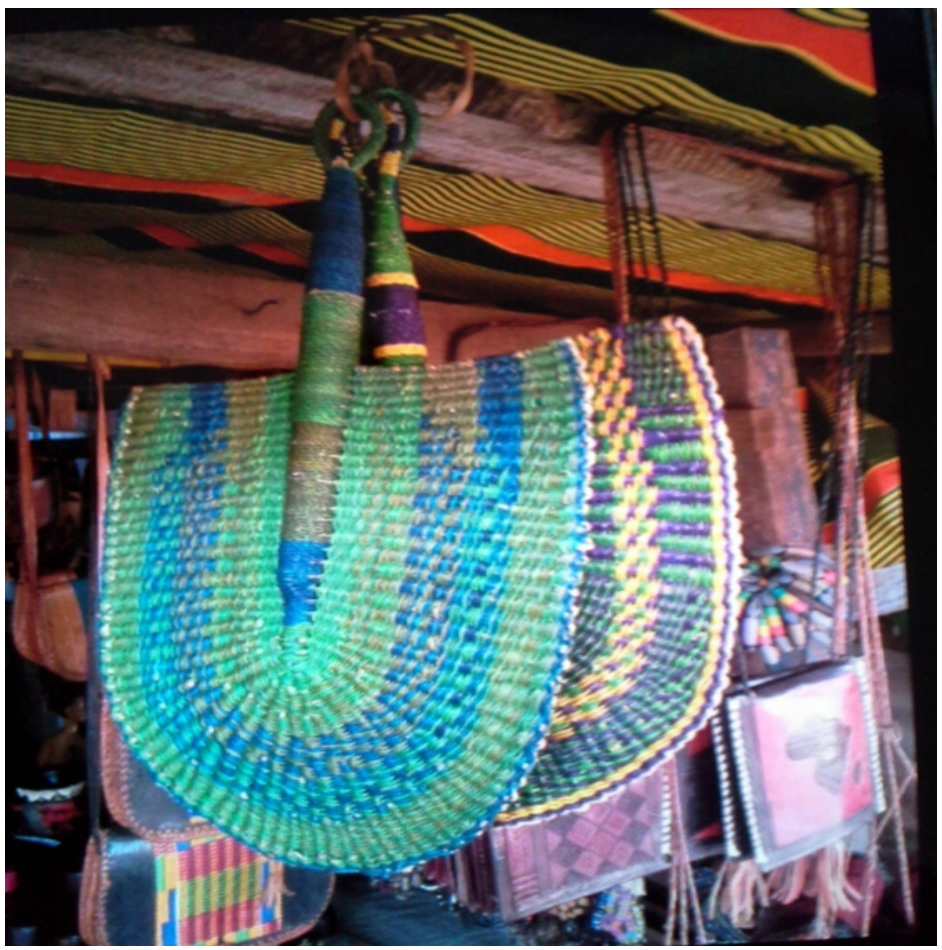

Hand fans made from panicum maximum.

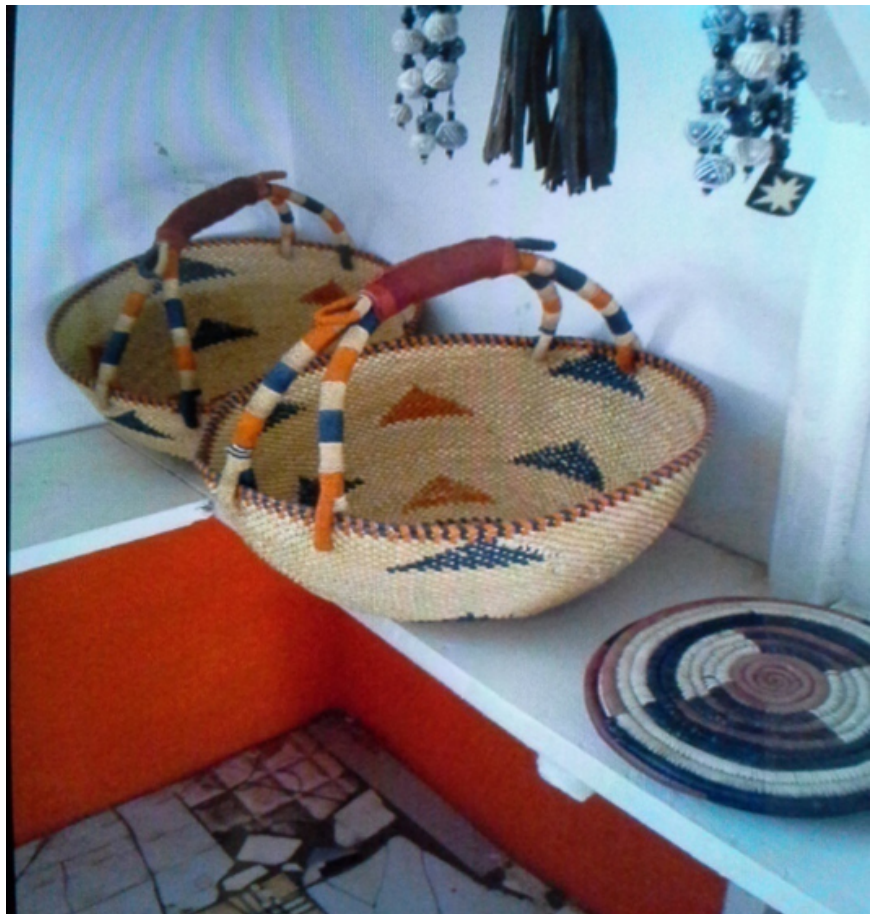

Fruits baskets and table mats

\section{Splitting of dry Panicum Maximum (Guinea grass):}

The researcher used an awl to pierce through the middle parts of the Guinea grass to open them. One half was held and the other half was pulled down to about half an inch to the end of the Guinea grass, the process was ended to make twisting easier. 


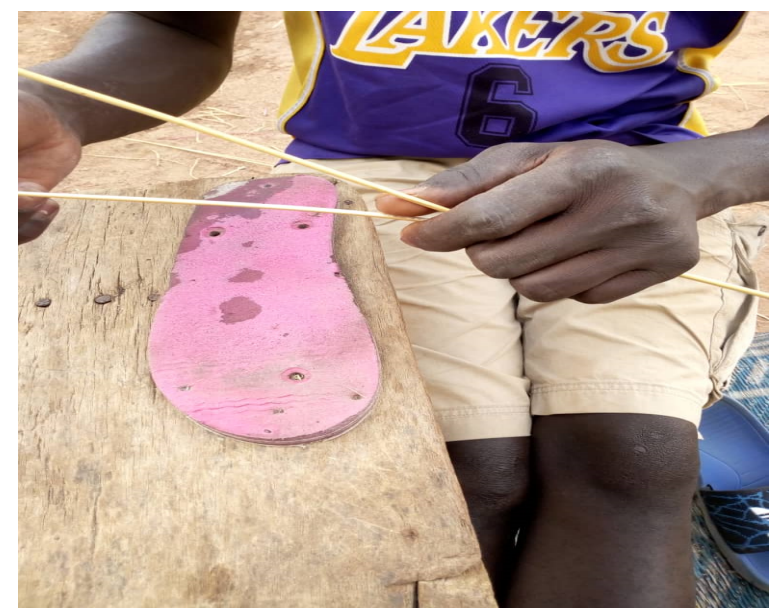

\section{Twisting of dry Panicum Maximum (Guinea grass):}

The split Guinea grass straws were bundled and soaked in water to keep them wet and to also prevent them from breaking during the twisting process. After which the split straws were placed on a rubber soul and twisted by rubbing vigorously with the palm for them to be twisted to form ropes. The twisted Guinea grass ropes were bundled for dyeing.

\section{Dyeing of Panicum Maximum (Guinea grass):}

In dyeing the materials, researchers boiled water in a metal pot at a temperature of about 100 degrees and added local dyes and salt to the boiling water. Afterwards, the twisted Guinea grass bundles were submerged in the dyed water with the support of a heavy load. These were allowed to boiled for about 45 minutes and eventually removed and spread on a clean surface to cool, dry and was ready for weaving.

\section{To produce flower vases with the techniques of integrating Panicum Maximum (Guinea grass)}

Pots were made on a manually operated potter's wheel and dried to leather-hard state, they were trimmed by turning excess clay from the bottoms to create footings for stability, make them lighter, and less likely to crack during drying and firing. Evenly spaced holes of $2 \mathrm{~cm}$ intervals were pierced through the top ends of the pots to serve as channels for weaving nodes. Decorative patterns were again incised on the surfaces to facilitate the pasting of the Guinea grass for surface decoration.

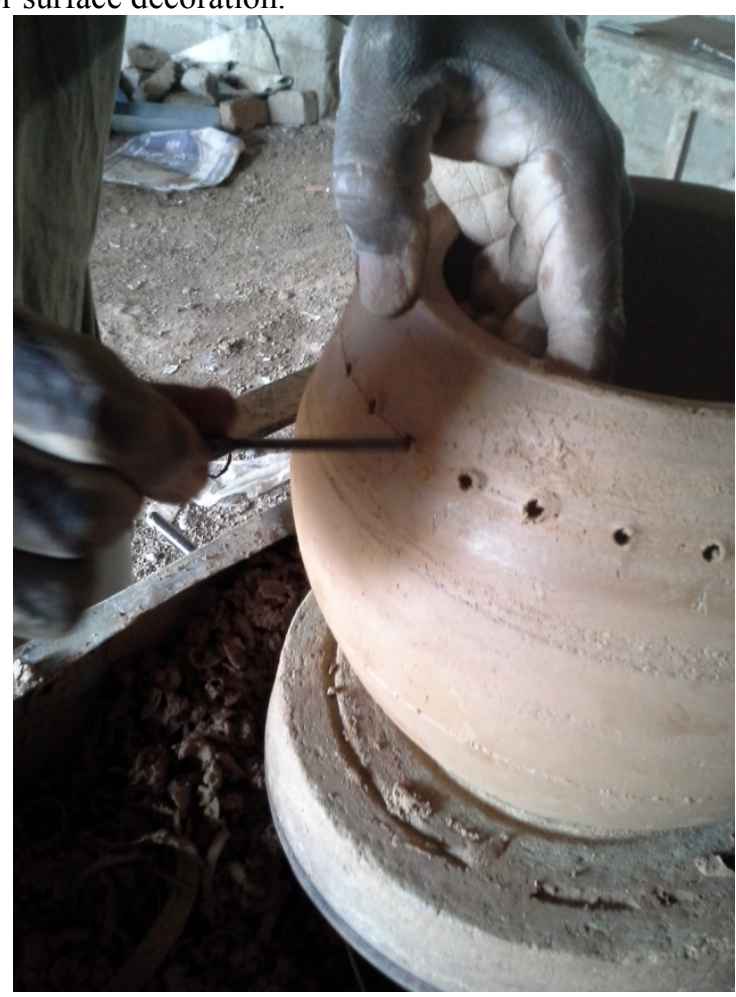

Piercing of holes for panicum weaving 


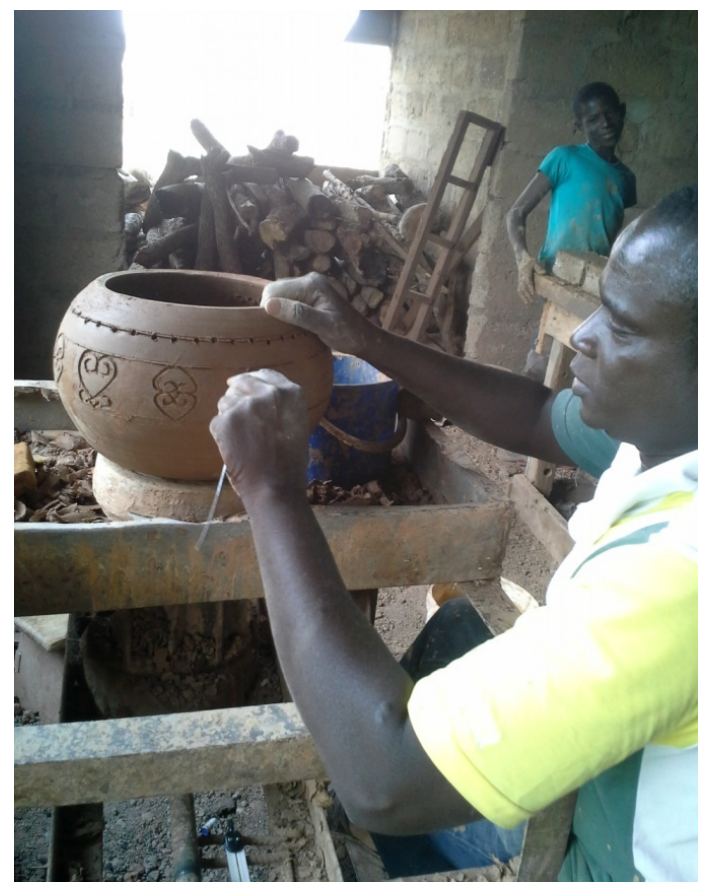

Decorating the pot to serve as base.

\section{Firing of clay pots.}

After the turned wares got to bone dry state, they were packed in a firewood kiln for firing. The firing process begun with pre-heating, where the heat was introduced gradually on the wares for about three hours to drive off the physical and chemically combined water. The firing temperature was gradually increased to full blast, which also lasted to about six hours until the pots were well fired. The firing was stopped and the kiln was allowed to cool down.

\section{Integrating Panicum maximum and the Fired Clay pots.}

The process started out with twisted panicum maximum (Guinea grass) straws used as spokes were passed through the holes of the clay pots to set the stage for weaving over the clay pots to complete the vase in production.

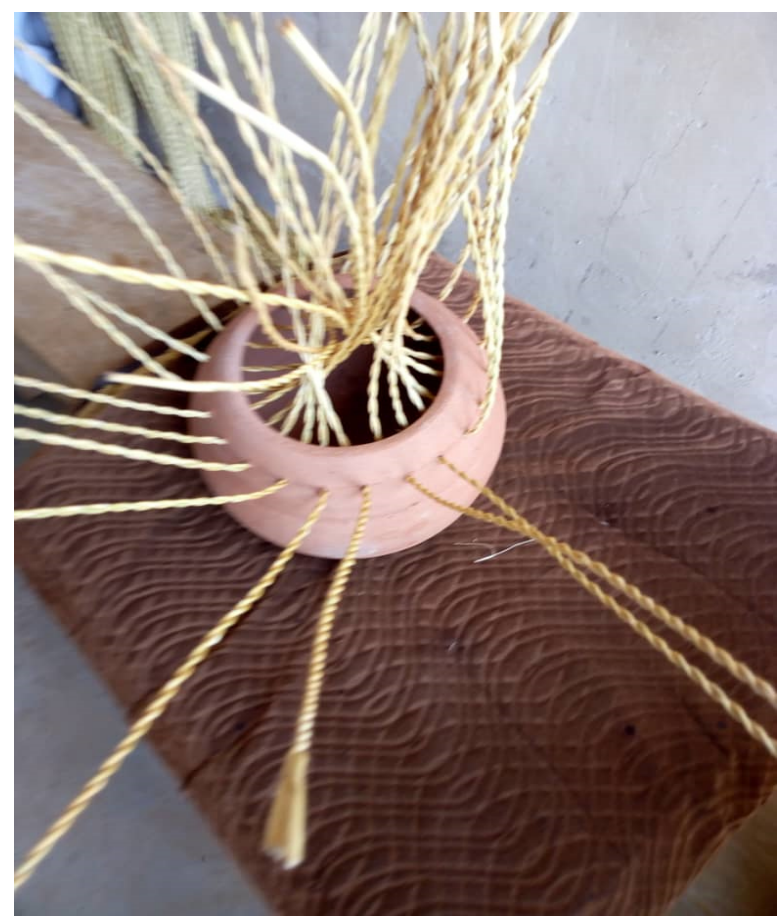

Spokes inserted in the pot 
Then, series of Panicum Maximum (Guinea grass) twisted strands were woven over and under the spokes frames to produce the sides of the woven structures.

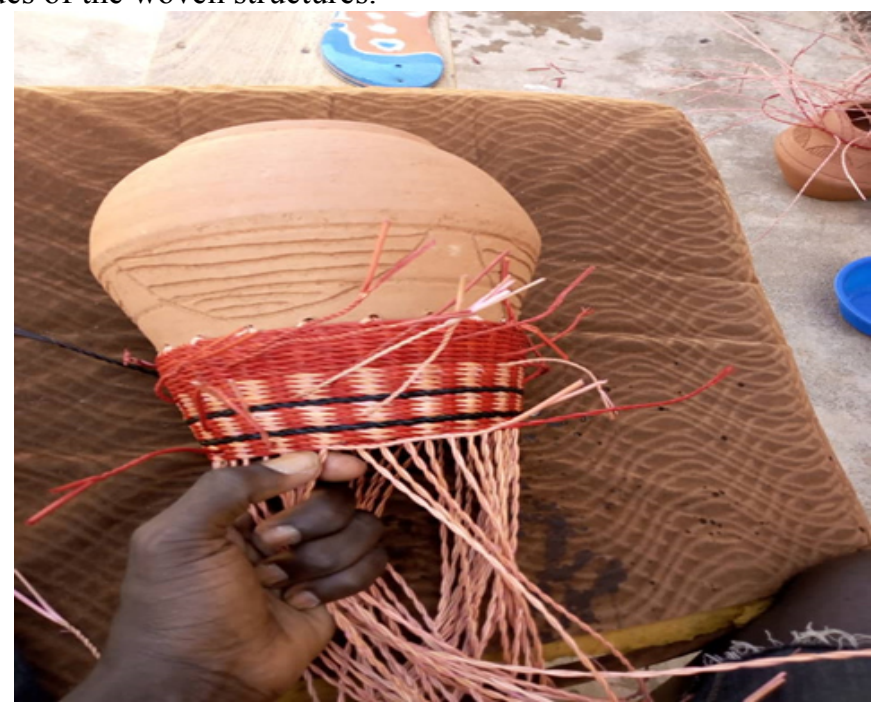

\section{Surface Decoration}

After the weaving had been completed, the researcher decorated the surfaces of the pots by applying white glue onto the incised patterns and glued some processed and selected Panicum Maximum (Guinea grass) firmly on the pots to decorate the product.

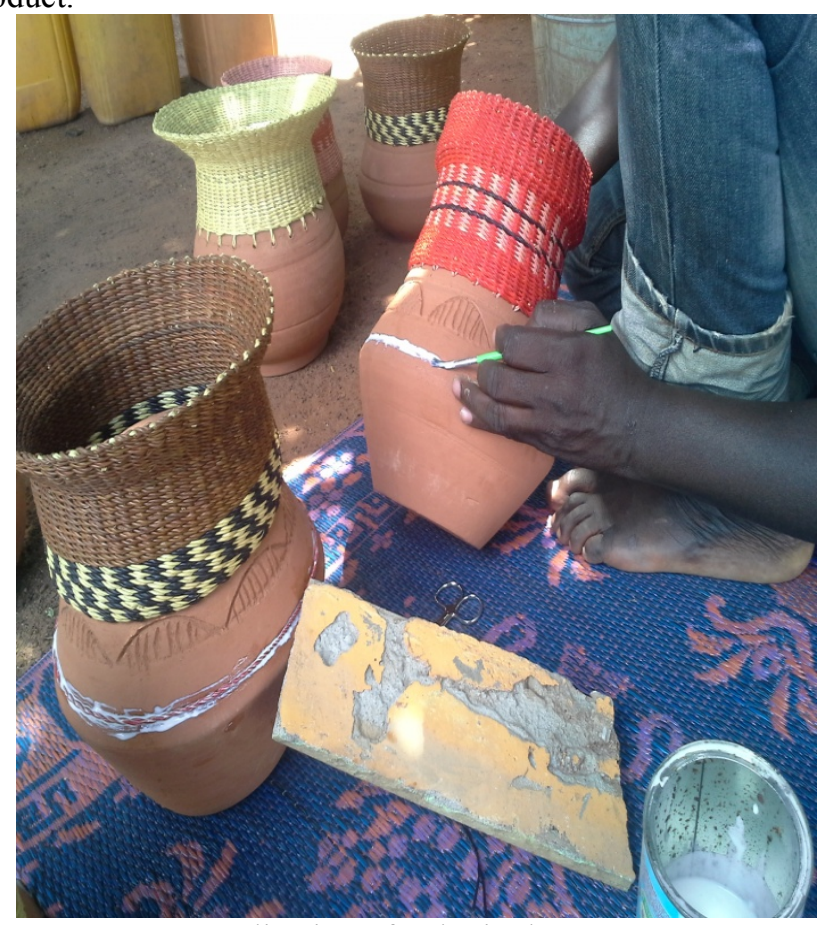

Application of polyvinyl acetate 


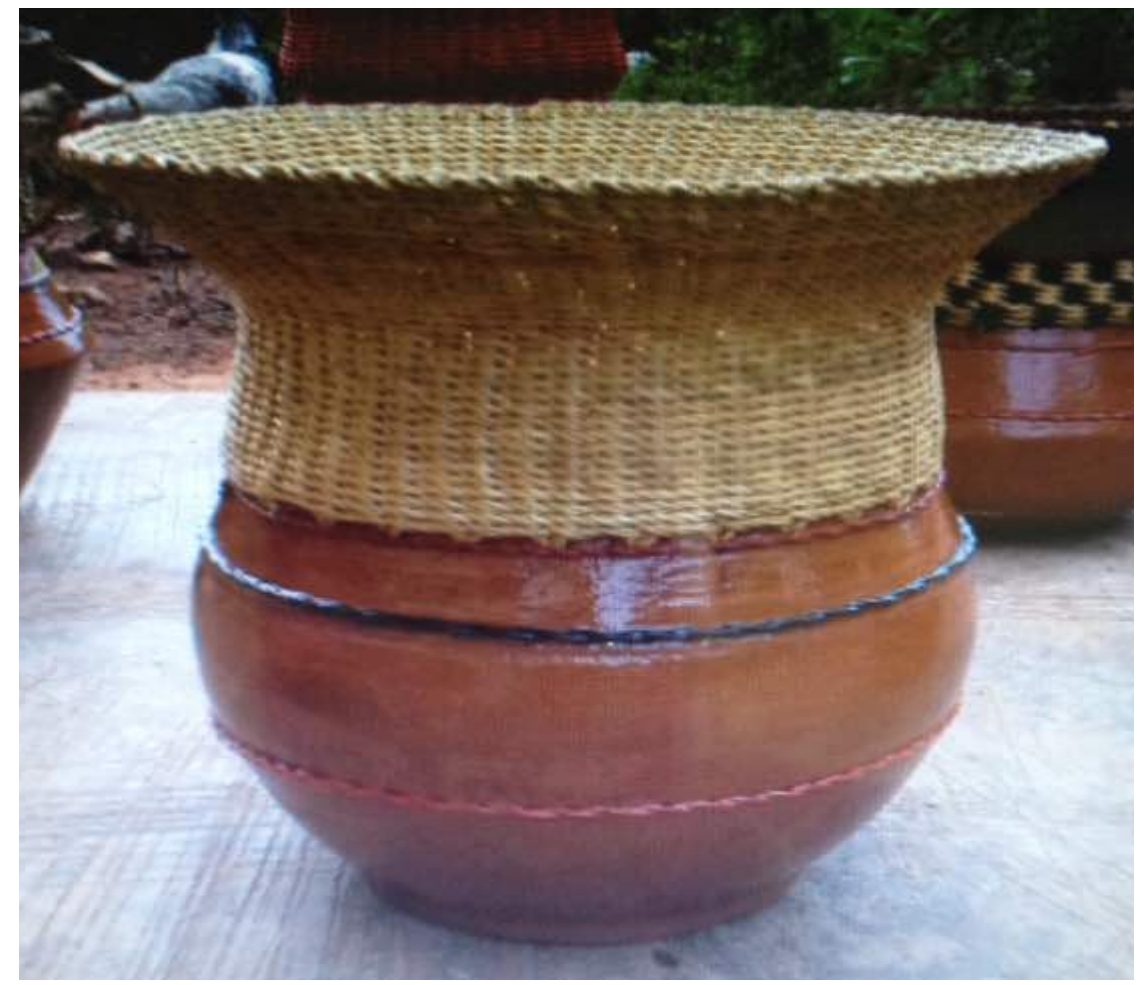

Integrated Clay and Panicum maximum product.

\section{The landscape and subtleties of old-style art.}

Old style art are the result of the response and the creative reaction of a people to nature. Steiner (2014) said this is the outcome of man's encounter with nature in an attempt to create a meaningful way of life for headlong development. It forms a minute yet vital part of the culture of a people, he concluded. Effa-Ababio (2005) said culture is the human achievement in nature and it involves the whole of life. It is within the frame work of culture that pottery, basketry and other traditional arts evolved. Traditional arts in divers' forms were made and used in most cultures for communication, i.e. storing information and passing on information or ideas, beliefs, traditions, trade and commerce, moral values and standing, identification, titles, religion, medicine and science. All these Effa-Ababio (2005) said are constituents' parts of culture and are the products of the achievements of man in nature.

\section{Integration of clay and panicum maximum, a human achievement}

The creative potentials of man were first experienced in the time of Adam and his wife Eve. The eyes of Adam and Eve were opened when they ate of the tree of which God commanded them not to eat, they saw they were naked and made aprons out of fig leaves for their covering. (Genesis 3.v7). The need for covering was as a result of their ability to perceive with a new understanding of their environment. Their source of material was nature and the motivation factor was need. Integration of clay and panicum maximum, is not by accident but by design because it evolved out of a need, a desire to achieve. It is an activity that was discovered and has the ability to be bequeathed to latter generations for advancement, thus becoming an achievement or part of the sum total of achievements of a people. Effa-Ababio (2005) said culture is evolved and conserved for posterity. He explained that the Almighty God created the world and created man and placed at his disposal the world of nature, his environment and gave him the power and ability to utilize nature to facilitate and enhance his life and what he achieves from his encounter with nature becomes his culture and material integration is not an exemption. Arnorld (1993) said that culture is the love of perfection. He further explained that culture is everything. If culture is everything then Integration of clay and panicum maximum, is not an exception. Effa-Ababio (2005) said that man 'purposiveness and endeavors in his encounter with nature distinguish culture from nature.

Traditional pottery making and weaving of panicum into products like baskets has been in practice among people of all nations from time immemorial and in Ghana the culture of using traditionally produced pots and locally woven plant fibers for mats and containers represented the main domestic way of life. These arts are believed to have started from the time immemorial.

\section{Conclusion}

The purpose of this piece of writing was to scan and make clear the natural history of clay and panicum 
maximum in Ghana. The study has suggested that Integration of clay and panicum maximum, is one of the products of human happenstance with nature. From the analysis so far, pottery and making of products with panicum maximum is an integrated system of belief, values and traditions and can be relied on for cultural development. The reason for the craft is common for most cultures and forms a tie connecting people of different cultural backgrounds. This will undergo vast changes and growth through creativity, and commercial activities. In pursuit of development and advancement, several innovations will evolve helping man to develop an evolution, and a way of existence that will draw inspiration from early times.

\section{References}

Botha, C. \& Botha, J. 1996. Bring Nature back to your garden. Wildlife and Environmental Society, Durban.

Chippendall, L.K.A. \& Meredith, D. 1955. The grasses and pastures of South Africa. Central News Agency, Pretoria.

Gibbs Russell, G.E., Watson, L., Koekemoer, M., Smook, L., Barker, N.P., Anderson, H.M. \& Dallwitz, M.J. 1990. Grasses of southern Africa. Memoirs of the Botanical Survey of South Africa No. 58: 10, 11.

Jackson, W.P.U. 1990. Origins and meanings of names of South African plant genera. Botanical Society of South Africa, Cape Town ..

Van Oudtshoorn, F. 1999. Guide to grasses of southern Africa. Briza Publications, Pretoria.

Amenuke,S,K. Dogde B.K, Asare F.D.K, Ayiku R.K., Baffoe A.(1991) General Knowledge in Art. Afrique Publications Ltd Ghana.

Arnorld M. (1993) Culture and Anarchy, Cambridge University, Cambridge,UK.

Coles Janet and Robert Budwig. (1990) ALL ABOUT BEADS London.: Dorling Kinsley Limited,

Effa Ababio (2005) Nature and dynamics of culture. Journal of science and technology KNUST Press Kumasi Ghana. Vol. 25 numbers 2.

THE BIBLE king James (2002) Zondervan Grand Rapids, Michigan, USA.

Huxley, A. (2005) Learning Commons- What is culture? Quotation of culture www.3pjobs.com/culturefit. $9_{\text {sp }}$. Amenuke S.K.(1995) Seminar on Development of Art for Teachers of Art. 